\title{
La ciudad bajo la lupa. Un análisis del espacio público y los sujetos en relación a los sistemas de video vigilancia
}

\author{
Vanesa Lio $^{1}$
}

\author{
Categoría: Documento \\ Fecha de recepción: 28 de mayo de 2012 \\ Fecha de aprobación: 27 de junio de 2012
}

\begin{abstract}
Resumen
En los últimos años, el uso de Circuitos Cerrados de Televisión (CCTV) para vigilancia, históricamente restringido al ámbito privado, ha evidenciado un desplazamiento hacia el sector público, implementándose estas técnicas en el marco de políticas públicas de prevención del delito y control social. El presente trabajo pretende analizar de qué manera la presencia de estas cámaras y la reproducción de las imágenes por ellas captadas en los medios de comunicación masiva incide en la construcción de una geografía determinada de la ciudad, así como también de los propios sujetos que la habitan.
\end{abstract}

Palabras Clave: Control social, Video-vigilancia, Inseguridad, Espacio público, Sujetos.

\begin{abstract}
In recent years, the use of Closed Circuit Television (CCTV) for surveillance, historically restricted to the private sector, has shown a shift towards the public sector, being implemented in the framework of public policies on crime prevention and social control. This paper analyzes how the presence of these cameras and the reproduction in the mass media of the images captured by them impact on the construction of a particular geography of the city and its subjects.
\end{abstract}

Key words: Social control, Video surveillance, Insecurity, Public space, Subjects.

1 Licenciada en Ciencias de la Comunicación. Graduada de la Facultad de Ciencias Sociales,UniversidaddeBuenosAires(Argentina).Contacto:vanesa_lio@hotmail.com 
La ciudad bajo la lupa. Un análisis del espacio público y los sujetos en relación a los sistemas de video vigilancia - Vanesa Lio

\section{Introducción}

En cada vez más ciudades del mundo, una persona que camina por las calles y los parques, utiliza transporte público o asiste a espectáculos masivos, es captada por cientos de cámaras de seguridad y sus acciones son grabadas en forma permanente.

Si bien la instalación de Circuitos Cerrados de Televisión (CCTV) para vigilancia estuvo históricamente restringida al ámbito privado, en los últimos años se produjo un desplazamiento de estas técnicas hacia el sector público, asumiéndose como una política estatal de prevención del delito, mayor control de los desórdenes sociales y disminución de las situaciones peligrosas. La aplicación de herramientas tecnológicas para el monitoreo de espacios públicos no sólo se ha desplegado en grandes y multitudinarias ciudades, sino incluso en comunidades o barrios pequeños.

En el caso argentino, este hecho se ha evidenciado, particularmente, en el territorio de la Provincia de Buenos Aires como respuesta a los índices de delitos y al aumento de la preocupación de la sociedad por esta problemática. Desde 1999, la cantidad de denuncias de hechos delictivos a nivel nacional comienza a aumentar, manteniéndose estable a partir de $2003^{2}$. En el caso de la Provincia de Buenos Aires, los delitos contra la propiedad y los homicidios dolosos registrados han evidenciado un aumento sostenido desde 1997, alcanzando su pico más alto en el año $2002^{3}$. Y, si bien la inquietud por el tema venía aumentando desde principios de la década del '90, en 2004 la inseguridad pasó a ocupar el primer puesto entre los problemas nacionales (Kessler, 2008). En este contexto, y en concordancia con la materialización

2 Sistema Nacional de Información Criminal Año 2008. Informe TOTAL PAÍS. Ministerio de Justicia, Seguridad y Derechos Humanos de la República Argentina.

3 Sistema Nacional de Información Criminal Año 2008. Informe Provincia de Buenos Aires. Ministerio de Justicia, Seguridad y Derechos Humanos de la República Argentina. 
en Argentina del discurso preventivo en torno a las políticas de seguridad que se evidencia en el mismo período (Hener y Niszt Acosta, 2004), la aplicación de las tecnologías en el campo de la seguridad ha dado lugar a nuevos mecanismos de control social y los sistemas de monitoreo público urbano se presentan, fundamentalmente, como herramientas para la prevención de delitos en el plano local.

El presente trabajo pretende analizar de qué manera la presencia misma de estas cámaras y la reproducción de las imágenes por ellas captadas en los medios de comunicación masiva inciden en la construcción de una geografía determinada de la ciudad, así como también de los propios sujetos que la habitan.

\section{Aspectos metodológicos}

La investigación se ha centrado en dos casos de estudio, correspondientes a los municipios bonaerenses de La Plata y Tigre. La elección de los mismos se ha basado en motivos diversos.

El partido de Tigre cuenta con un total de 376.381 habitantes $^{4}$, que lo ubican cerca de la media entre los municipios que componen el Gran Buenos Aires, y ha exhibido un notable crecimiento en los últimos diez años ${ }^{5}$. Ha sido un distrito pionero en la implementación de sistemas de vigilancia del espacio público con CCTV. Su plan municipal de monitoreo satelital fue inaugurado en marzo de 2008, un año antes del lanzamiento del Programa Integral de Protección Ciudadana, destinado a facilitar la incorporación de este tipo de tecnología en materia de seguridad en los municipios bonaerenses ${ }^{6}$. Luego de tres años, el sistema se ha

4 Fuente: Instituto Nacional de Estadística y Censo (INDEC). Censo Nacional de Población, Hogares y Viviendas 2010.

5 En términos poblacionales, ha evidenciado un crecimiento del 25 por ciento entre 2001 y 2010. Fuente: INDEC.

6 El Programa Integral de Protección Ciudadana se ha puesto en marcha en abril de 2009, como resultado de un convenio de cooperación firmado por la Jefatura 
La ciudad bajo la lupa. Un análisis del espacio público y los sujetos en relación a los sistemas de video vigilancia - Vanesa Lio

extendido y diversificado como ningún otro. El municipio cuenta actualmente con 500 cámaras y la proyección de alcanzar un total de 800, pero ha avanzado hacia la integración de todos los sistemas de CCTV existentes en la zona, tanto del ámbito público como privado. Incluye, además, la participación activa de la comunidad y constituye uno de los ejes comunicacionales de la gestión municipal.

La Plata, por su parte, es la capital de la Provincia de Buenos Aires y cuenta con una población total de 654.324 habitantes $^{7}$. La implementación de su sistema de monitoreo con CCTV se ha enmarcado en el programa de alcance provincial destinado a tal fin y cuenta actualmente, según informaciones difundidas por el propio municipio, con unas 200 cámaras de seguridad en todo el partido. La particularidad en el caso de La Plata es que la geografía de la ciudad ha sido un aspecto central de la estrategia municipal desde su puesta en marcha, delimitando zonas de riesgo a partir de la colocación de los dispositivos. En el nivel comunicacional, este elemento ha cobrado especial relevancia durante el periodo de campaña electoral del Intendente hacia su re-elección en octubre de 2011.

El corpus de análisis incluyó los planes desarrollados por cada uno de los municipios en materia de vigilancia del espacio público con videocámaras, así como también los principales canales comunicacionales utilizados en relación a esta temática por los gobiernos locales: sitios web institucionales y redes sociales.

Asimismo, se han incluido noticias y artículos periodísticos publicados por medios gráficos en versiones impresas y digita-

de Gabinete de Ministros de la Nación y el Ministerio Seguridad del Gobierno de la Provincia de Buenos Aires. El programa consiste en la asignación de recursos nacionales no reintegrables a diversos municipios bonaerenses destinados a incorporar tecnología en materia de seguridad para la prevención de delitos.

7 Fuente: Instituto Nacional de Estadística y Censo (INDEC). Censo Nacional de Población, Hogares y Viviendas 2010. 
les, seleccionándose un medio de alcance nacional y tres medios locales para cado uno de los $\operatorname{casos}^{8}$.

A los fines de analizar la difusión de los videos captados por las cámaras de seguridad se han utilizado como fuentes los sitios web municipales, otras plataformas digitales como Youtube y Facebook, y el programa televisivo Cámaras de Seguridad .

El diseño de investigación ha sido predominantemente de tipo cualitativo, abordándose el problema principalmente mediante el análisis discursivo. La elección de esta metodología permitió explorar relaciones y situaciones que se dan en el ámbito social. Las herramientas cuantitativas fueron utilizadas sólo a los fines de verificar algunos datos a partir de la medición de variables y regularidades en el corpus de análisis.

\section{El panóptico urbano}

Las políticas de seguridad han alcanzado, sobre todo a partir del comienzo del nuevo siglo, una centralidad cada vez mayor en las planificaciones de gobierno, tanto a nivel nacional como provincial y municipal. Como consecuencia, se produjo una intensificación de los mecanismos de control social dirigidos a la prevención del delito y una mayor intervención del Estado en los espacios públicos, aumentando la iluminación en las calles, enrejando plazas y parques o instalando sistemas de vigilancia continua con cámaras distribuidas por la ciudad.

Los mecanismos de poder que en las sociedades disciplinarias actuaban al interior de las instituciones de control se trasladan,

8 La base documental mediática ha incluido artículos publicados entre enero y junio de 2011 en Diario Clarín, como medio gráfico de tirada nacional; El Día, Diagonales y Hoy para el caso de La Plata; Diario Lo Nuestro, Agencia de Noticias Infoban y Zona Norte Diario para el municipio de Tigre.

9 Programa que se emite semanalmente (los días miércoles en el horario de 22.30 a 23.30) por la señal de aire América TV desde mayo de 2011. Se han utilizado, para el análisis, cinco emisiones correspondientes al mes de junio de 2011. 
La ciudad bajo la lupa. Un análisis del espacio público y los sujetos en relación a los sistemas de video vigilancia - Vanesa Lio

de esta forma, a la totalidad de la sociedad y a los espacios públicos. Y la intervención sobre los cuerpos, convertidos en "cuerpos dóciles" a través de la disciplina, se extiende a todos los individuos, adiestrándolos para una vigilancia continua (Foucault, 1975: 142). En las sociedades contemporáneas, las denominadas "sociedades de seguridad", el delito se presenta en el marco de una serie de acontecimientos probables y las reacciones del poder frente a ese fenómeno implican un cálculo de costos (Foucault, 1978: 21, 40). La administración de los riesgos aparece, entonces, como un nuevo y poderoso mecanismo de control vinculado al biopoder, un poder que se ejerce positivamente sobre la vida e implica controles precisos y regulaciones generales (Foucault, 1978: 15). Así, el objetivo real del aparato biopolítico no sería penalizar infracciones, sino controlar la peligrosidad.

La aplicación de estos sistemas de monitoreo público urbano nos remite, de algún modo, a esa realidad descripta por George Orwell en 1984, donde absolutamente todo podía ser visto por el ojo del Gran Hermano. Es, a escala social y ampliada, el gran panóptico de las instituciones disciplinarias, que permite mantener una vigilancia constante sobre el conjunto de la población y regular así su accionar.

“Es visto, pero él no ve (...) De ahí el mayor efecto del Panóptico: inducir en el detenido un estado consciente y permanente de visibilidad que garantiza el funcionamiento automático del poder" (Foucault, 1975: 204).

La mirada vigilante del estado municipal ejerce así su poder sobre los ciudadanos. Los operadores en los centros de monitoreo pueden ver, en teoría, todo lo que sucede en la ciudad. Se pasa así a las "sociedades de control", donde la crisis de las instituciones ha dado lugar a un tipo de control aplicado de forma sistemática en espacios abiertos (Deleuze, 1990: 115-116).

La aplicación de estas técnicas de videovigilancia en espacios públicos no es un descubrimiento local. Los sistemas del Monitoreo Público Urbano (MOPU) de La Plata y el Centro de Operacio- 
nes (COT) de Tigre reproducen experiencias de grandes capitales y centros urbanos del mundo. Se encargan de monitorear la ciudad durante las veinticuatro horas del día, visualizando y controlando las imágenes captadas por las cámaras distribuidas en los lugares considerados de mayor peligrosidad, y dando aviso a la fuerza policial ante accidentes, delitos o hechos sospechosos.

Es que las últimas décadas han demostrado que la vigilancia, siguiendo los pasos de la modernidad, se ha convertido en un fenómeno globalizado. Su gran expansión, sobre todo en el hemisferio norte, se produjo con mayor velocidad a partir de 1970 luego de la computarización. Desde 1980, se fue globalizando crecientemente a medida que aumentó la movilidad de las poblaciones y las relaciones sociales y transacciones ya no estuvieron tan sujetas a las limitaciones espaciotemporales (Lyon, 2004: 139). Pero, a partir del ataque de las Torres Gemelas el 11 de septiembre de 2001, las formas de vigilancia se han diversificado. Sin embargo, tienen algo en común: todas, por alguna razón, colocan bajo escrutinio a las poblaciones. Es decir, durante siglos la observación y el control estuvieron dirigidos a fines específicos y momentos delimitados. Durante el siglo XX, en cambio, la vigilancia se convirtió en una rutina (Lyon, 2002: 2). Las ciudades se han transformado, así, en enormes panópticos y es esa "mirada sin ojos" la que genera un impacto en la naturaleza misma del espacio público. La cuestión no es el control del crimen sino el control en un sentido más amplio: la vigilancia se convirtió en un mecanismo para garantizar la visibilidad y, junto con ella, la exclusión de los "temidos extraños" (Koskela, 2000: 260).

\section{Las imágenes como producto mediático}

Ahora bien, ¿cómo se construye el consenso social acerca de los delitos que deben mantener alerta a la población? ¿Quién estipula cuáles son los hechos y quiénes son las personas sobre las cuales se deberá hacer foco? En este punto cobra especial relevancia un elemento que se ha acrecentado notablemente en el 
La ciudad bajo la lupa. Un análisis del espacio público y los sujetos en relación a los sistemas de video vigilancia - Vanesa Lio

último tiempo: el acceso público a ciertas imágenes captadas por los sistemas de monitoreo. Como fenómeno paralelo -quizá consecuente- a la implementación de los sistemas de vigilancia por CCTV, recientemente se ha podido verificar en Argentina la puesta a disposición de las imágenes captadas por las cámaras de seguridad a través de diversos mecanismos.

En primer lugar, algunos municipios publican estos videos a través de sus sitios web y redes sociales como Facebook y Youtube. En segundo lugar, y aún más importante, estas imágenes han tomado cada vez mayor protagonismo en los medios de comunicación masiva. Incluso, la circulación de las imágenes captadas por estos sistemas de monitoreo ha dado lugar, en Argentina, a la llegada al aire televisivo del programa Cámaras de Seguridad, destinado exclusivamente a reproducir (luego de su previa selección y edición) lo que captan las cámaras de vigilancia. Y entra aquí también en juego la política comunicacional adoptada por cada Municipio, que entrega este material no sin un previo recorte.

En la propuesta de Ferrer (2005), las redes mediáticas e informáticas se presentan como orientadoras de la visión y como voluntades de poder que pretenden instaurar una matriz total al interior de la cual un modo de pensar y de vivir queda enmarcado y desde la cual el mundo se expone ante nosotros. Las nuevas tecnologías de la visión se insertan cada vez más en la vida cotidiana con total naturalidad, al tiempo que "fijan formas en lo visible". De esta manera, regulan la "voluntad de ver", orientan la atención visual, señalan perspectivas convenientes. Así planteado, "las verdades visuales que se exponen en esos marcos no son imágenes del mundo sino un mundo sólo asible bajo la forma de la imagen" (Ferrer, 2005: 29).

Las instituciones y poderes de turno han hecho uso de la "máquina visual" para potenciar su impulso y sesgarla con cierta intencionalidad ideológica. 
“La máquina visual es el ensamblaje de metáforas lumínicas del conocimiento, espacios institucionales y arquitectónicos y tecnologías de las visualización, cuya articulación despliega un espacio existencial donde se pone al descubierto una verdad de época" (Ferrer, 2005: 33).

De esta forma, los sistemas de monitoreo tienen un impacto directo en la vida social y re-organizan, de cierta forma, a las multitudes. Si bien cada vez tenemos más acceso a las imágenes captadas de la ciudad en la que vivimos, es preciso destacar que nunca accedemos a la totalidad de ellas. Estamos, en cambio, habilitados a ver sólo un recorte que decide alguien más, ya sea el propio municipio o los medios de comunicación, que vuelven a imponer una impronta determinada exenta de toda objetividad. Justamente, los editores y diseñadores de imágenes en los espacios mediáticos cumplen funciones estético-políticas. Porque controlar la percepción significa fundar una soberanía política y lo que hoy se designa como realidad debió ser legitimado y creído como una verdad visible (Ferrer, 2005: 121).

En las últimas décadas, nuevos enfoques de los estudios de la comunicación han puesto el eje sobre el concepto de construcción social de la realidad, planteándose investigar las formas en que los medios modelan el conocimiento que el sujeto tiene de ella (Barata, 2003: 488). Sin embargo, existe una identificación entre los órdenes del discurso de la realidad y del discurso sobre la realidad que responde a la visión naturalizada sobre la capacidad de los medios de mostrar, objetivamente, lo que pasa a través de sus fuentes y del conocimiento que dicen tener sobre la opinión pública (Martini, 2009: 23). Y, en este punto, se da un proceso de retroalimentación continua:

“El verosímil construido por la noticia periodística legitima sus fuentes en esa 'realidad' a la que por lo general la sociedad accede a través de los discursos de los mismos medios, que se convierten en fuentes para otros discursos sociales e institucionales" (Martini, 2009: 23). 
La ciudad bajo la lupa. Un análisis del espacio público y los sujetos en relación a los sistemas de video vigilancia - Vanesa Lio

De esta forma, no sólo se construye la realidad sino también lo que se entiende por inseguridad ciudadana, delimitándose el esquema simbólico sobre el orden y la moralidad, determinando qué y quién es correcto (Barata, 2003: 590-510).

Veo, veo... ¿qué ves?

Un elemento central en el análisis es la observación de aquello que están mirando los sistemas de vigilancia por CCTV, en qué lugares específicos y en qué sujetos se detiene esa mirada vigilante.

En primer lugar, se ha podido observar que las políticas de control y represión del delito que ponen en práctica los estados municipales a través de los sistemas de monitoreo de los espacios públicos centran su atención en delitos menores, poniendo el eje en aquello definido por el Realismo de Derecha como pequeñas incivilidades (Wilson y Kelling, 1982: 70). Tanto en La Plata como en Tigre, se asume que las formas delictivas de mayor impacto para la seguridad son aquellas vinculadas a delitos contra la propiedad, hurtos, actos de vandalismo y robos callejeros. Incluso, el temor no se focaliza sólo en la posibilidad de ser víctima de un delito, sino también en el miedo a ser molestado por gente indisciplinada. En este sentido, estos programas apuntan a elevar el nivel de orden público en los barrios (Wilson y Kelling, 1982: 77). La reiterada mención en estos proyectos a las "situaciones sospechosas" a la par de los "hechos delictivos" o "circunstancias peligrosas", lleva inevitablemente a preguntarse qué es lo sospechoso y cómo lo determinan las cámaras.

Al mismo tiempo, la comunidad asume un rol fundamental en tanto se considera necesaria su contribución en la lucha contra el delito. La Secretaría de Protección Ciudadana de la Municipalidad de Tigre, que tiene bajo su órbita al COT, incluye entre sus objetivos "coordinar las relaciones entre las policías y los vecinos". Por otro lado, se introducen tecnologías destinadas a la intervención de la comunidad en la prevención del delito, como las "columnas anti-pánico", que forman parte del MOPU de La 
Plata. En esta línea, se busca fortalecer los mecanismos de control informales y la interacción de la fuerza policial con la comunidad local.

Con lo cual, los sistemas reconocen, en primera instancia, dos grupos de sujetos que se presentan como excluyentes: los delincuentes o disturbadores del orden público, sobre los cuales las cámaras deben focalizar su atención; y los vecinos o ciudadanos, de los cuales se requiere su colaboración para que estos sistemas funcionen.

Con el surgimiento de una nueva condición post-social a partir del Neoliberalismo ha sido necesario replantearse qué significa gobernar la in/seguridad. Entre las transformaciones que caracterizan esta etapa, es posible reconocer un desplazamiento de la defensa de la sociedad a la gestión focalizada de los niveles de inseguridad en las comunidades, surgiendo como resultado intervenciones de carácter puntual, local y situativo (De Marinis, 2004: 67). De esta forma, se produce un heterogéneo mosaico de zonas caracterizadas por sus diferentes niveles de seguridad y peligrosidad que requieren de la aplicación de políticas específicas.

Incluso, la gran expansión de estos sistemas ha generado "el miedo a los espacios no vigilados": mientras más se extiendan los CCTV como norma, más pelearán las áreas excluidas por ganar en cobertura (Graham, 2002: 139). La incorporación de técnicas digitales y algorítmicas a estos sistemas de CCTV ha permitido desarrollar un tipo de monitoreo automatizado que busca algo "anormal" o "inesperado". Esto, sumado a la utilización de tecnologías de base de datos por imágenes, ha llevado a prácticas sociales discriminatorias o racistas a partir de la generación de estereotipos y tipologías de lo anormal o amenazante (Graham, 2002: 140). Es que la videovigilancia modifica la forma en la cual es ejercido el poder, modifica las experiencias emocionales en el espacio urbano y afecta la forma en la cual la "realidad" es conceptualizada y entendida (Koskela, 2000: 250). La vigilancia 
La ciudad bajo la lupa. Un análisis del espacio público y los sujetos en relación a los sistemas de video vigilancia - Vanesa Lio

contribuye, como sostenemos aquí, a la producción del espacio urbano.

\section{Dos casos, una misma lógica}

El tema de la inseguridad pone en cuestión, a su vez, la definición de su opuesto. Es decir, hay que determinar qué elementos permiten establecer los niveles de "seguridad". En este aspecto, es central la instalación de la temática en la agenda pública y los criterios que son privilegiados a partir de ella.

"En general, las políticas de gobierno y los medios masivos básicamente centralizan el tema de la inseguridad en la cuestión del delito callejero o del crimen callejero" (Daroqui et al., 2003: 2).

La prevalencia de este tipo de inseguridad y el relegamiento de otras inseguridades es también percibido en el abordaje que realizan los medios de comunicación de esta temática.

"La inseguridad es un significante salido de las entrañas del discurso periodístico sobre el crimen, que terminó remplazando metonímicamente a delito (...) Las otras inseguridades han quedado relegadas o invisibilizadas" (Martini y Pereyra, 2009: 13-14).

Es en este marco de afianzamiento de la noción de "inseguridad" relacionada al delito y de la prevalencia de acciones estatales orientadas a la prevención que surgen las nuevas modalidades de vigilancia del espacio público, como herramientas para reducir al "pequeño delito desorganizado". En Argentina, el monitoreo de espacios públicos en manos del Estado aparece ya avanzada la primera década del siglo XXI, siendo el municipio de Tigre el primero en implementarlo y el que mayor expansión y difusión ha logrado en los últimos años. Pero la extensión de estos sistemas de videovigilancia en la Provincia de Buenos Aires ha encontrado su mayor impulso a partir de la creación y puesta en marcha en abril de 2009 del Programa Integral de Protección 
Ciudadana, surgido de un convenio de cooperación firmado por la Jefatura de Gabinete de Ministros de la Nación y el Ministerio Seguridad del Gobierno de la Provincia de Buenos Aires. En este contexto se inscribe el segundo de los casos seleccionados para el análisis, el de la ciudad de La Plata.

La extensión, por parte del gobierno provincial, de la videovigilancia en los municipios bonaerenses deja entrever, entre otras cosas, sobre qué tipo de delitos se está haciendo foco desde las políticas de seguridad. El objetivo principal de estos sistemas es "identificar las situaciones de peligro" a partir de la "ayuda de los ojos tecnológicos"10. Se pone la atención en los "lugares clave", considerados "lugares de riesgo", para que "el Estado se anticipe desde la prevención" con el fin de "cuidar la vida"11. Pero aquí habría que detenerse a analizar qué se considera una situación de peligro y dónde están los riesgos.

La intención de controlar a los jóvenes, la focalización en las drogas y el alcohol como principales problemáticas, y la atención a situaciones que "alteran el orden público" son algunos de los elementos que muestran cómo estos mecanismos se centran, al igual que los realistas de derecha, en las pequeñas incivilidades. Si bien, en primera instancia, las cámaras están destinadas a vigilar y controlar a la totalidad de la población, lo cierto es que estos mecanismos terminan por poner en el centro de la escena a los grupos sociales considerados como "indisciplinados", entre los que incluyen a mendigos, borrachos, adictos, adolescentes ruidosos, prostitutas, vagabundos y personas mentalmente perturbadas (Wilson y Kelling, 1982: 68). En este punto, otro de los conceptos interesantes en este análisis es el de "sujetos desviados". Siguiendo a Becker (1963), la "desviación" es una mala acción

10 Discurso del Gobernador Daniel Scioli en ocasión de inauguración de un sistema con 40 cámaras de seguridad en el municipio de Berisso. Buenos Aires, 13 de octubre de 2010. Disponible en www.prensa.gba.gov.ar.

11 Discursos varios del Gobernador Daniel Scioli en mayo de 2011. Disponibles en www.prensa.gba.gov.ar. 
La ciudad bajo la lupa. Un análisis del espacio público y los sujetos en relación a los sistemas de video vigilancia - Vanesa Lio

que ha sido etiquetada públicamente como tal como resultado de una iniciativa de alguien.

"Antes de que un acto sea visto como desviado, y antes de que ningún tipo de persona sea etiquetada y tratada como marginal por la comisión de ese acto, alguien tiene que haber creado la norma que establece ese comportamiento desviado" (Becker, 1963: 181).

Lo que sea catalogado como desviado y, por lo tanto, requiera de mayor atención de los operadores en los centros de monitoreo es, entonces, consecuencia de un proceso de interacción entre las personas. Para que exista desviación es preciso que sea definida con anterioridad la norma y ésta es siempre creada y aplicada por alguien con un interés propio. Luego, el Estado desarrolla mecanismos para responder a una cuestión instalada en la opinión pública y sobre la que se ha logrado que la gente sienta que hay que hacer algo al respecto. Pero, al mismo tiempo, los videos de las cámaras de seguridad construyen a los sujetos e instalan, de algún modo, en la sociedad las causas del miedo.

En el Municipio de Tigre la seguridad es entendida como "un derecho" y la protección ciudadana se presenta como "un valor" que involucra "a todas las personas"12. En este sentido, se apela a la participación activa de la comunidad, a la cual se otorga un papel protagónico. La misma Secretaría de Protección Ciudadana de la Municipalidad de Tigre tiene entre sus objetivos "coordinar las relaciones entre los policías y los vecinos". En esta línea, se introducen las distintas tecnologías para la participación de la comunidad y se pretende mostrar una responsabilidad compartida en la lucha contra el delito. En la descripción del Plan Alerta del sitio web del COT se expresa:

12 "Daniel Scioli y Sergio Massa inundan de patrulleros a Tigre". Diario Lo Nuestro, 06 de junio de 2011. 
"La comunidad de Tigre ha diseñado, durante los últimos tres años, un sistema de protección ciudadana municipal para colaborar con el gobierno de la Provincia de Buenos Aires, quien tiene bajo su responsabilidad la seguridad de sus habitantes"13.

Se presenta aquí al gobierno municipal y a los vecinos de Tigre como pares, ambos integrantes de esta comunidad creadora del plan y que contribuye a través de sus acciones con las fuerzas policiales provinciales. El municipio pone a disposición la red, a través de la instalación de cámaras, del centro de monitoreo, de la provisión de operadores para el mismo, de la compra de móviles propios para el patrullaje y de la puesta en funcionamiento de los distintos mecanismos para realización de denuncias. Los vecinos, por su parte, son los encargados de iniciar el flujo de información, enviando sus alertas mediante el sistema POS en comercios, mensajes de texto desde teléfonos celulares, la página web del COT, los botones de pánico ubicados en colectivos y escuelas, y los 2.000 vigiladores privados que se incorporaron al sistema. Si bien está claro que no existe tal paridad, se define así a un grupo social al que se le asigna un rol de asociado al poder estatal en la "lucha contra el crimen", evidenciando también que no todos los habitantes de la ciudad son miembros de la mencionada comunidad.

Asimismo, hay una gran focalización en las víctimas, término que aparece siempre contrapuesto al de delincuente. Se excluye, así, toda posibilidad de que quien es delincuente pueda también ser considerado una víctima. Las significaciones que giran en torno a este concepto remiten sólo a un modo de ser víctima atado a la noción de inseguridad como delito, a la que venimos haciendo referencia.

13 Sitio web del Centro de Operaciones Tigre y el Plan Alerta: www.alerta.tigre. gov.ar 
La ciudad bajo la lupa. Un análisis del espacio público y los sujetos en relación a los sistemas de video vigilancia - Vanesa Lio

Al mismo tiempo, los videos difundidos de los CCTV van construyendo una cierta geografía de la ciudad que está determinada por el miedo, los riesgos y la peligrosidad. Esta construcción, puramente subjetiva, condiciona el uso de los espacios públicos, que comienzan a ser catalogados como seguros o inseguros de acuerdo al nivel de vigilancia que en ellos se opere.

En el caso de Tigre, estas imágenes que dejan una huella en el entramado social son difundidas tanto a través de medios de comunicación masiva como por los canales propios del Municipio. En este sentido, se utiliza tanto el sitio web como los perfiles en redes sociales como Facebook y Youtube. Entre los videos de robos, persecuciones y choques automovilísticos, se mezclan otros hechos de bastante singularidad, como la detención de dos jóvenes por trasladar un ganso en una mochila ${ }^{14}$ o hechos que "perturban el orden público"15, tan "amenazantes" para el vecino como el caso de un hombre que, recién llegado de un pueblo del interior de la provincia, decide bañarse en una fuente de agua ubicada en el ingreso al municipio de Tigre, agregando un elemento fuera de lugar en la postal turística.

En el caso de los videos emitidos en medios de comunicación masiva, la regularidad en el estilo de la edición, la musicalización, los subtítulos, las inscripciones gráficas y la utilización de herramientas de resaltado sobre la imagen permiten confirmar que es la gestión municipal la que entrega los videos ya editados y listos para su reproducción.

Como se ha mencionado, la puesta a disposición de las imágenes captadas por los sistemas de monitoreo municipales de distintas ciudades dio lugar, en mayo de 2011, a la llegada al aire televisivo del programa "Cámaras de Seguridad". Con una emi-

14 "Tigre: una mochila con sorpresa", 19 de julio de 2011. Disponible en http:// www.youtube.com/watch?v=BWBpDrY58yA

15 "Las cámaras lo limpiaron", 17 de enero de 2011. Disponible en http://www. youtube.com/user/policialestigre\#p/u/41/fjHVwwiTH0w. 
sión semanal de una hora de duración, está destinado casi exclusivamente a reproducir el material tomado por las cámaras de vigilancia.

De las emisiones seleccionadas para el análisis, se ha podido detectar que en sólo el 21,8\% de los videos exhiben casos de robos o hurtos en la vía pública. El resto se divide entre peleas callejeras $(21 \%)$, personas borrachas $(9,2 \%)$, accidentes automovilísticos $(7,6 \%)$, exhibicionismo (6,7\%), "situaciones sospechosas" (2,5\%), los jóvenes en la noche $(3,4 \%)$, violencia de género $(1,7 \%)$ y otras situaciones (21\%), entre las que se pueden mencionar, a modo de ejemplo, sucesos tan disimiles como animales sueltos, picadas de motos, pintadas en la vía pública, incendios, despedidas de solteros y gente durmiendo en la calle ${ }^{16}$.

Al mismo tiempo, tanto la elección como la forma de presentar los videos del Municipio de Tigre implica una determinada manera de caracterizar a los sujetos y construye el espacio urbano en que estos se desenvuelven a partir de la oposición seguro-inseguro. Se presenta, así, una imagen de los buenos vecinos amenazados por el crimen, comprometidos todos ellos con una mayor participación ciudadana en pos de colaborar en la vigilancia y el control social, en contraposición con los grupos amenazantes, procedentes de las minorías sociales o los sectores marginales, que deben ser mantenidos bajo la lupa en forma permanente a fin de evitar situaciones que disturben el "orden público". Dos parejas comen hamburguesas en la puerta de un local de comidas rápidas cuando un joven "revoltoso y desafiante" co-

16 Los porcentajes fueron obtenidos en base a la observación y clasificación de los videos incluidos en las cinco emisiones del programa televisivo Cámaras de Seguridad que conforman el corpus de análisis del presente trabajo (miércoles $1^{\circ}$ de junio de 2011, miércoles 8 de junio de 2011, miércoles 15 de junio de 2011, miércoles 22 de junio de 2011 y miércoles 29 de junio de 2011). A los fines del presente trabajo, se entiende por "video" a toda aquella composición audiovisual generada a partir de la edición de las imágenes captadas por las cámaras de seguridad en el espacio público que, por sus características y su delimitación espacio-temporal, puede ser considerada una unidad narrativa con un comienzo y final determinados. 
La ciudad bajo la lupa. Un análisis del espacio público y los sujetos en relación a los sistemas de video vigilancia - Vanesa Lio

mienza a molestarlos y "piropear a las mujeres", impidiéndoles "comer tranquilos" por estar "bajo los efectos del alcohol". Una mujer circula con su auto cuando un "limpiavidrios delincuente" irrumpe su rutina robándole sus pertenencias personales en un semáforo de El Talar. Es una mañana cualquiera en un colectivo de la línea 720, cuando "un grupo de violentos se toma a golpes de puño ante la atónita mirada del resto de los pasajeros atemorizados". Una "amenaza latente" también se hace presente en la línea 721, cuando "un violento bajo los efectos de la droga o con sus facultades alteradas" se atrevió a "dirigirse al interior de la unidad sin pagar el correspondiente boleto" ${ }^{\prime 17}$.

Los revoltosos, violentos y delincuentes, por un lado. Los vecinos, trabajadores y ciudadanos, por otro. Las situaciones, cotidianas como se presentan, parecen buscar una automática identificación en los espectadores. La polaridad con que se muestran los roles sociales, al mismo tiempo, obliga al espectador a decidir de qué lado está: vigilante o vigilado. Las imágenes ponen así ante los ojos de los vecinos la ciudad en la que viven, construyen el espacio de interacción y regulan las relaciones sociales.

En el caso de La Plata, el plan se ha presentado, desde el primer momento de su instalación en junio de 2009, con el objetivo de monitorear los "principales focos delictivos y/o conflictivos del municipio". Uno de los ejes iniciales en los que estuvo basado el MOPU fue la instalación de cámaras de seguridad en edificios y predios municipales, con el fin de "controlar y resguardar" dichos espacios y "mantener bajo observación las zonas o lugares críticos que escapan al recurso humano". La atención focalizada en estos predios municipales tiene que ver con que, por ser áreas de grandes dimensiones, son consideradas "susceptibles

17 "Tigre: se pelearon por una hamburguesa y terminó preso", “Tigre: las cámaras atrapan a un limpiavidrios delincuente", "Tigre: colectivero alertó con botón de pánico y atraparon a violentos con las cámaras", "Tigre: descontrolado en colectivo es atrapado por botón de pánico". Todos los videos y textos están disponibles en www.youtube.com/user/policialestigre 
de distintas clases de delitos o actos de vandalismo". Por otro lado, el foco de atención está puesto en zonas que concentran mayor nivel de tránsito, tanto vehicular como peatonal, hecho que las convierte en "áreas de riesgo" y, por lo tanto, demandantes de "protección" municipal. En este sentido, fueron creados los corredores comerciales de la ciudad, dando especial interés a la instalación de cámaras y monitoreo de estos lugares de "paseo y consumo" para brindar "mayor seguridad a los comerciantes y vecinos". Por el mismo motivo, estos corredores son también el lugar elegido para la instalación de los denominados Dispositivos de Emergencia o Botón Anti-pánico, que se presentan como un complemento a las cámaras de vigilancia y son consideradas "una herramienta para brindar seguridad".

En esta línea y apelando a la misma lógica, en abril de 2011 el Concejo Deliberante de La Plata aprobó el "Código de Espectáculos Públicos, Actividades Recreativas y de Nocturnidad", el cual establece, entre otras cosas, que las discotecas y restobares deben instalar una cámara de seguridad en sus ingresos, a los fines de "extremar las medidas de prevención y seguridad para el público asistente"18. Un mes más tarde, el Consejo Escolar platense anunció la creación de una Comisión de Seguridad con el objetivo de "estudiar los hechos de vandalismo en los establecimientos educativos e instalar cámaras en las escuelas" en función del trazado de un "mapa de inseguridad escolar" y con el fin de "prevenir los hechos vandálicos"19. Así comenzó la instalación de cámaras en 26 escuelas platenses, previéndose que todas ellas sean monitoreadas desde la central del MOPU. A esto se sumó, en el mes de junio de 2011, el anuncio de la Municipalidad de

18 Ordenanza 10.799 del Concejo Deliberante de la Ciudad de La Plata, sancionada el 20 de abril de 2011. Disponible en http: / / www.concejodeliberante.laplata.gov.ar / digesto/or11000/or10799.htm

19 Actualmente el monitoreo y control de los sistemas está a cargo de una empresa privada, pero el objetivo tanto del Consejo Escolar como de los funcionarios municipales es que el monitoreo de estas cámaras se centralice también en el MOPU. 
La ciudad bajo la lupa. Un análisis del espacio público y los sujetos en relación a los sistemas de video vigilancia - Vanesa Lio

La Plata acerca de la colocación de cámaras de seguridad en las inmediaciones de varias escuelas, decisión tomada a raíz de una serie de enfrentamientos entre estudiantes de distintos colegios que tuvieron lugar en la vía pública.

De esta forma, se fue configurando de a poco un mapa de los lugares de riesgo de la ciudad, a partir de la distribución de las cámaras de seguridad en función de "estudios de índices delictuales" realizados por las autoridades municipales. Se coloca, al mismo tiempo, a ciertos grupos sociales bajo la mira, siendo los jóvenes, en este caso, uno de los grandes focos de atención.

La puesta a disposición de imágenes en el caso de La Plata es mucho menor, apareciendo sólo unos pocos videos en su portal de la red social Facebook y en el programa televisivo Cámaras de Seguridad. Sin embargo, en este municipio, la distribución misma de las cámaras de vigilancia parece cobrar especial relevancia en la construcción de una geografía determinada de la ciudad y en la caracterización de los sujetos que en ella habitan. Los mapas aparecen de forma recurrente para graficar diversas cuestiones relacionadas con el delito y las políticas de seguridad adoptadas. Se presta, además, especial atención a la difusión en la prensa de la colocación de nuevos dispositivos y a la comunicación permanente de la localización de las cámaras. Es que, en la información policial, el crimen aparece asociado con la peligrosidad que se le atribuye a determinados espacios urbanos y suburbanos (Pereyra, 2009: 41), y en función de esto es que se va construyendo un mapa del espacio público absolutamente segmentado y ponderado a partir de los niveles de riesgo.

La colocación de las cámaras de seguridad, entonces, aparece totalmente conectada a los peligros que se atribuyen a cada zona. Así, la concentración de gente en las áreas comerciales de las calles 8 y 12 de la ciudad de La Plata, por ejemplo, hace subir el termómetro del riesgo y, por lo tanto, estos corredores deben ser estrictamente vigilados. 
Desde la descripción y justificación del propio plan de videovigilancia en la ciudad de La Plata se expresa que la localización sucesiva de las cámaras fue determinada de manera estratégica en función de un estudio de los índices delictuales existentes y del mapa del delito. Pero, al mismo tiempo, el término "delito" suele ser sustituido metonímicamente por expresiones como "situaciones sospechosas", "circunstancias peligrosas" o "actos de vandalismo". Es decir, las cámaras no son únicamente una herramienta de prevención del delito sino que los operadores deben también emitir una señal de alarma ante este tipo de situaciones que les resulten "extrañas" o "anormales". Una vez más, se presenta la dificultosa tarea de entender qué es lo sospechoso o peligroso, quién lo determina y por qué está habilitado para hacerlo.

A partir de lo que las cámaras deben mirar y de lo que las imágenes dejan ver, se van definiendo los sujetos sociales que interactúan en el espacio público. Por un lado, el buen vecino y el comerciante de la ciudad, víctimas amenazadas por el avance del delito, a quienes el Estado debe dar respuestas para brindar mayor seguridad y prevención. Por el otro, como para el Realismo de Derecha, las minorías sociales y los jóvenes en tanto siempre potenciales victimarios (Di Iulio et al., 1995).

\section{Conclusiones}

Estos panópticos sociales parecen estar dedicados, en primera instancia, a extender la mirada vigilante a la totalidad de la población, poniendo así a todas las personas bajo sospecha y generando, como consecuencia, un efecto disuasivo producto de que la comunidad sabe que está siendo vigilada, pero no puede saber en qué momento ni por quién. La mirada vigilante está en manos de un Estado municipal que ejerce así su poder sobre los ciudadanos y aplica un tipo de control sistemático en espacios abiertos. Todos somos, en principio, objeto de observación de estos "ojos tecnológicos" distribuidos por la ciudad. 
La ciudad bajo la lupa. Un análisis del espacio público y los sujetos en relación a los sistemas de video vigilancia - Vanesa Lio

Sin embargo, la utilización de estas herramientas demuestra la focalización de la mirada en ciertos lugares y grupos sociales. Estos dispositivos están destinados a la persecución de disturbios callejeros y ponen la atención en las "pequeñas incivilidades". El tipo de delito captado por los sistemas de videovigilancia demuestra que los mismos están enfocados en mantener el orden público, buscando no sólo evitar hechos delictivos sino también controlar ciertas "irregularidades" sociales como la mendicidad, el alcoholismo, las adicciones y la prostitución, consideradas todas ellas "situaciones de riesgo". De la misma manera, los jóvenes se presentan como potenciales disturbadores del orden público y, por lo tanto, objeto de atención. Estas políticas apuntan, así, a controlar a los adolescentes como estrategia para evitar que se conviertan en delincuentes.

Por otro lado, los videos captados por los sistemas de monitoreo y puestos a disposición de la comunidad cumplen un rol central en la construcción de la geografía de la ciudad y de sus habitantes. En primer lugar, hay que recordar que el espacio público es, justamente, el lugar de emergencia de los sujetos, donde tanto los actores como la política misma cobran forma. Así, la intervención de estos dispositivos de control tendrá inevitablemente una consecuencia sobre la delimitación del mismo y, por ende, en la forma en que los sujetos asuman sus roles. En este punto, el papel de las imágenes en circulación se presenta como fundamental. Por un lado, por el acceso a visualizar a la ciudad en que vivimos de una manera que pretende ser total y mediada por unos "ojos tecnológicos" que, emulando a nuestros propios ojos, intentan ser transparentes. Por otro lado, porque, como expresa Ferrer (2005), estas tecnologías de la visión insertadas en la vida cotidiana fijan formas en lo visible, regulando la voluntad de ver y orientando la atención.

El poder de turno hace uso de la "máquina visual" para potenciar su impulso y sesgarla con cierta intencionalidad propia. Es importante remarcar que, de esta intervención, surge un recorte 
de las imágenes a las cuales tendremos acceso. Justamente como consecuencia de esa selección se va construyendo el espacio y los sujetos de una manera determinada. Las imágenes presentan con cierto nivel de polaridad los roles de los grupos sociales: por un lado, los delincuentes; por otro, las víctimas.

Controlar la percepción significa fundar una soberanía política y, en este sentido, especial atención prestarán quienes se disputan el poder por ubicar su "verdad visible" como realidad legitimada. En nuestros casos de análisis, este poder está en manos de los Estados municipales, dueños de las imágenes y decisores de lo que debe ser mostrado (y bajo qué forma).

Sin embargo, como hemos visto, es también a partir de la colocación misma de las cámaras de seguridad que se van delimitando los lugares de riesgo de la ciudad. La concentración de gente y la circulación de jóvenes parecen indicar mayores niveles de peligro y, por lo tanto, estos espacios aparecen como los preferidos por la mirada vigilante del Estado. Al mismo tiempo, la insistencia en la delimitación de ciertas zonas como peligrosas lleva a elevar el sentimiento de inseguridad en las personas, generándose así un círculo vicioso.

¿Son los niveles delictivos los que definen ciertos espacios como más peligrosos y, entonces, plausibles de vigilancia? ¿O es la colocación misma de las cámaras la que define a un lugar como riesgoso y eleva el sentimiento de inseguridad percibido por las personas en esa zona? La instalación de estos sistemas de videovigilancia por CCTV ha ido delimitando así un mapa específico de las ciudades en el que las cámaras aparecen como indicadores de mayores niveles de peligro y, a su vez, como dadoras de protección.

\section{Bibliografía}

Barata, Francesc (2003). “Los mass media y el pensamiento criminológi$\mathrm{Co}^{\prime \prime}$, en Bergali, Roberto, Sistema penal y problemas sociales / Valencia, Editorial Tirant lo Blanch, pp. 487-511. 
La ciudad bajo la lupa. Un análisis del espacio público y los sujetos en relación a los sistemas de video vigilancia - Vanesa Lio

Becker, Howard (1963). "Iniciativas morales", en Outsiders, (2009) / Buenos Aires, Siglo Veintiuno.

Daroqui, Alcira, Kaminsky, Gregorio y Pergoraro, Juan. “Inseguridad. Conversaciones entre Alcira Daroqui, Gregorio Kaminsky y Juan Pegoraro", Revista Argumentos, Número 3 (2003) / Buenos Aires, Instituto de Investigaciones Gino Germani, pp. 1-25.

De Marinis, Pablo. "In/seguridad/es sin sociedad/es: cinco dimensiones de la condición postsocial" en Muñagorri, I. y Pegoraro, J. La relación seguridad-inseguridades en centros urbanos de Europa y América Latina. Estrategias, políticas, actores, perspectiva y resultados (2004) / Oñati, Dykinson, pp. 61110.

Deleuze, Gilles (1990). "Posdata sobre las sociedades de control", en Christian Ferrer (comp.) El lenguaje libertario: antología del pensamiento anarquista contemporáneo, (2005) / La Plata, Terramar, pp. 115-121.

Di Iulio Jr., John; Logli, Paul; Koch, Ed, et al. (1995). “Soluciones al crimen. 18 cosas que podemos hacer para luchar contra él", Delito y Sociedad. Revista de Ciencias Sociales, Números 15-16 (2001) / Buenos Aires, pp. 80-117.

Ferrer, Christian (2005). Mal de Ojo: el drama de la mirada, Buenos Aires, Colihue.

Foucault, Michael (1975). "Los cuerpos dóciles" y "El panoptismo", Vigilar y Castigar, (2002) / Buenos Aires, Siglo XXI Editores Argentina, pp. 139-174 y 199-230.

Foucault, Michael (1978). "Clase del 11 de enero de 1978", Seguridad Territorio y Población, (2006) / Buenos Aires, Fondo de Cultura Económica, pp. 15-44.

Graham, Stephen. "CCTV: The Stealthy Emergence of a Fifth Utility?" Planning Theory and Practice, (2002), Número 3, pp. 237241.

Hener, Alejandro y Niszt Acosta, Florencia. “La gestión preventiva del delito en el contexto de las nuevas racionalidades políticas neoliberales", V Congreso Nacional de Sociología Jurídica, (2004) / La Pampa, Universidad Nacional de La Pampa y Sociedad Argentina de Sociología Jurídica Argentina.

Kessler, Gabriel. "Sentimiento de inseguridad y miedo al crimen en Argentina", V Jornadas de investigación en Antropología 
social, (2008) / Buenos Aires, Facultad de Filosofía y Letras (UBA).

Koskela, Hille. "The gaze without eyes: video-surveillance and the changing nature of urban space", Progress in Human Geography 24 (2), (2000), pp. 243-265.

Lyon, David. "Editorial. Survillance Studies: Understanding visibility, mobility and the phenetix fix", Surveillnace \& Society 1 (1), (2002), pp. 1-7.

Lyon, David. "Globalizing Surveillance. Comparative and Sociological Perspectives". International Sociology 19 (2), (2004), pp. 135-149.

Martini, Stella. “El delito y las lógicas sociales. La información periodística y la comunicación política", La irrupción del delito en la vida cotidiana. Relatos de la comunicación política, (2009) / Buenos Aires, Editorial Biblos, pp. 21-40.

Martini, Stella y Pereyra, Marcelo. "Introducción", La irrupción del delito en la vida cotidiana. Relatos de la comunicación política (2009) / Buenos Aires, Editorial Biblos, pp. 11-17.

Pereyra, Marcelo. "Cartografías del delito, territorios del miedo", La irrupción del delito en la vida cotidiana. Relatos de la comunicación política, (2009) / Buenos Aires, Editorial Biblos, pp. 41-61.

Wilson, James y Kelling, George (1982). “Ventanas Rotas. La policía y la seguridad en los barrios", Delito y Sociedad. Revista de Ciencias Sociales, Números 15-16 (2001), Buenos Aires, pp. 67-79. 